\title{
Effect of Washing on Reducing Bacterial Loads in Common Vegetables Sold in Dhaka City
}

\author{
Ashish Kumar Das ${ }^{1}, Z_{\text {Zinia Sultana }}{ }^{1}$, Ahamed Kabir ${ }^{1}$ and Md. Shahidul Kabir ${ }^{*}$ \\ Department of Microbiology, Stamford University Bangladesh
}

\begin{abstract}
Vegetables and fruits can be contaminated with microorganisms from different sources during production and processing. Quality of vegetables usually relies on the quality of processing water and sanitizers used to reduce microbial load and increase shelf-life of vegetables. The present study demonstrates the role of washing on reducing bacterial loads in common vegetables sold in Dhaka city. A total of seventy two samples comprising of eighteen types of fresh vegetables were collected. Total heterotrophic bacteria, coliforms and Enterobacteriaceae were determined in 72 samples including potato, tomato, carrot, cucumber, green chilli, bean, eggplant, cauliflower, turnip, radish, capsicum, pumpkin, cabbage, gourd, papaya, bitter gourd, snake gourd and ridge gourd before and after washing with tap and filtered water, halotab water, bleaching powder $(0.2 \%)$ solution and bleaching powder $(0.2 \%)$ with citric acid $(0.1 \%)$ for 10 minutes. Tap water, filtered water, bleaching powder $(0.2 \%)$, halotab solution and bleaching powder $(0.2 \%)+$ citric acid $(0.1 \%)$ solutions were found to be effective and significantly reduced the bacterial loads in vegetables compared to the unwashed vegetables $(\mathrm{P}<0.01)$. Effect of washing vegetables using tap and filtered water were found to reduce load of total viable bacteria to $0.85-2.05 \log _{10} \mathrm{cfu} / \mathrm{g}$ and $2.38-3.36 \log _{10} \mathrm{cfu} / \mathrm{g}$, respectively compared to those of unwashed samples. The efficiency of washing for reducing the bacterial load depends on the quality of washing water used and the types of disinfectant solutions used. An appropriate washing technique can significantly reduce the bio burden in contaminated vegetables and may reduce the risk of foodborne infections associated with the consumption of vegetables.
\end{abstract}

Keywords: Vegetable, Disinfectant, Coliform, Bleaching powder, Food borne illness.

\section{Introduction}

Fresh fruits and vegetables are essential for good health but they may harbor both pathogenic and nonpathogenic microorganisms. Developing countries are producing and trading substantial amount of fresh vegetables to meet the increasing demand for vegetables and fruits world-wide. The growth of vegetables varies in different seasons of the year that suits their growth conditions. Vegetables can be contaminated from environmental sources during cultivation from soil, water, insects, air, birds, animal, equipment and marketing. Irrigation of vegetables with polluted water and fertilizers with animal and human wastes can aid in the transfer of enteric pathogens to fruits and vegetables ${ }^{1}$. Consumption of contaminated raw vegetable without adequate processing may cause foodborne infections and other enteric diseases ${ }^{2,3}$. Survival ability of the contaminating microorganisms in vegetables will depend on their physiological status and activity. Bruised vegetables will release essential nutrients and aid in the growth and multiplication of microorganisms ${ }^{4}$.

Generally vegetables retain $10^{3}$ to $10^{5}$ microorganisms $\mathrm{cm}^{-3}$ or $10^{4}$ to $10^{7}$ microorganisms $\mathrm{g}^{-1}$ if they are not washed properly. Some of the predominant bacterial types are lactic acid bacteria,
Corynebacterium, Enterobacter, Proteus, Micrococcus, Enterocoocus, Pseudomonas and several spore-formers. They may help to grow different types of moulds, such as Alternaria, Fusarium, and Aspergillus on their surfaces. Listeria monocytogens, Salmonella spp., Shigella spp., Clotridium botulinum, Clotridium perfringens and Escherichia coli are important pathogens reported to cause food borne infections associated with different vegetables ${ }^{5,6}$. Pathogenic bacteria isolated from vegetable samples have been reported to harbour virulence genes, toxins and enzymes responsible for the pathogenesis ${ }^{7,8}$. Hepatitis A and Norwalk-like viruses have been reported to be commonly associated with food borne illness ${ }^{9}$.

In recent years, producers, regulatory agencies and the consumers have become more concerned about the microbiological safety of fruits and vegetables. Produce related outbreaks of foodborne illness are more prevalent in many parts of the world. It was estimated that up to 2.7 million deaths worldwide and $1.8 \%$ of the total global disease burden were attributed to the consumption of contaminated fruits and vegetables ${ }^{10}$. A recent report from Centre for Disease Control and prevention (CDC) shows that each year 48 million people get sick, 128,000 people become

*Corresponding author:

Dr. Md. Shahidul Kabir, Professor, Department of Microbiology, Stamford University Bangladesh, 51 Siddheswari Road, Dhaka, Post code 1217, Bangladesh.

Phone: +8801949622783, Fax: +88-02-9143531

Email: kabir@stamforduniversity.edu.bd 
hospitalized and 3,000 people died from food borne diseases ${ }^{11}$. According to previous studies in the USA, most of the illnesses were linked to pathogenic bacteria and viruses ${ }^{11}$. A novel strain of Escherichia coli O104:H4 caused a serious outbreak in the northern part of Germany in $2011^{12}$.

Contamination of fresh food and vegetables are now concern all over the world. Increasing attention is being given to develop suitable methods to disinfect fresh produce and to remove pathogenic microorganisms from them. Most processors and consumers assume that washing and sanitizing fresh fruits and vegetables will reduce the microbial load. However, published data indicate that these conventional methods are not capable of reducing microbial populations on produce by more than 90.0 to $99.0 \%$, hence not efficient to assure microbiological safety. It is realized that conventional washing technology was developed primarily to remove soil from produce, not microorganisms. However, improvement in the efficiency has been reported with newer sanitizing agents such as chlorine dioxide, ozone and peroxyacetic $\operatorname{acid}^{13}$. Therefore, this study was carried out to determine the efficiency of different disinfectant solutions in reducing the bacterial load of different types of vegetables sold in Dhaka city.

\section{Materials and Methods}

\section{Sample collection}

Seventy two (72) fresh vegetable samples of eighteen (18) categories were collected randomly from different local markets and from street vans in Dhaka city between January 2014 and June 2014. Samples were collected early in the morning in a sterile plastic packet and transported to the laboratory in a cool box as soon as possible following standard methods. All samples were aseptically collected in sterile plastic bags and transported to the laboratory for processing. All samples were collected and processed following standard methods ${ }^{14}$.

\section{Sample Processing}

Samples were chopped with a sterile knife on a chopping board into small pieces and $5 \mathrm{~g}$ sample was added to sterile glass containers containing $45 \mathrm{ml}$ desired washing solution or water. Six containers were used for washing samples with washing solutions such as, normal saline $(0.85 \% \mathrm{NaCl}$, w/v), tap water, filter water, halotab (15 mg tablet in $2 \mathrm{~L}$ water) solution, $0.2 \%$ $(\mathrm{w} / \mathrm{v})$ bleaching powder solution, $0.2 \%(\mathrm{w} / \mathrm{v})$ bleaching powder plus $0.1 \%(\mathrm{w} / \mathrm{v})$ citric acid solution. One portion of sample was processed without washing. Samples were stirred gently for 10 minutes and excess washing solution was discarded. Both the washed and unwashed samples were grind in sterile mortar pestle in $9 \mathrm{ml}$ normal saline. Ground samples were diluted 1:10 using normal saline and plated for enumeration of bacterial load.

\section{Microbiological Analysis}

\section{Enumeration of total bacteria}

Homogenised samples were diluted to $10^{-1}$ to $10^{-6}$ and $100 \mu \mathrm{l}$ sample was inoculated on Nutrient Agar media (Oxoid, UK) by drop plate method. Plates were incubation at $37^{\circ} \mathrm{C}$ for $18-24$ hours after inoculation. Plates showing 30-300 colony forming unites (cfu) were counted to enumerate the bacterial load before and after washing.

\section{Enumeration of total coliforms}

Diluted samples $(100 \mu \mathrm{l})$ were inoculated on $\mathrm{mFC}$ agar (Himedia Laboratories, India) by drop plate method and incubated at $37^{\circ} \mathrm{C}$ for 18-24 hours. Plates were examined for characteristic blue colonies for total coliforms.

\section{Enumeration of total Enterobacteriaceae}

Violet red bile salt glucose (VRBG) agar media was used to enumerate total Enterobacteriacae in diluted samples. Plates were incubation at $37^{\circ} \mathrm{C}$ for $18-24$ hours. Purple and pink colour colonies were counted as Enterobacteriaceae.

\section{Statistical Analysis}

Statistical analysis was done by using online software available at http://www.socscistatistics. com/. Student t-test was done for two independent means. Samples were analyzed by two tail test at significance level 0.01. Samples showing $P$ value $<0.01$ was considered significant reduction compared to the unwashed samples.

\section{Result and Discussion}

Vegetables are popular meal and regularly taken with other food items in Bangladesh like many countries of the world. Washing vegetables can either reduce microbial load or may contaminate them depending on the quality of washing water. Washing water may be contaminated from food handlers, grazing animals and faecal sources and act as vehicles for transmission of pathogens to raw produce ${ }^{10,15}$. Outbreak of food borne diseases due to consumption of contaminated vegetable may put the public health at serious risk. Consumption of contaminated raw, unprocessed and inadequately cooked vegetables may cause foodborne infections ${ }^{16}$. The present study shows the role of washing on reduction of the load of pathogenic bacteria in common vegetables consumed in Bangladesh.

Table 1 shows the total bacterial cell count in unwashed and washed vegetables. The highest and lowest counts of total heterotrophic bacteria in unwashed vegetables were $9.07 \pm 0.41$ and $8.33 \pm 0.49 \log _{10} \mathrm{cfu} / \mathrm{g}$ in green chili and bitter gourd, respectively. After washing with tap and filtered water their total bacterial counts ranged between $7.86 \pm 0.60-6.84 \pm 0.47$ and $6.34 \pm 0.51-5.14 \pm 0.43 \log _{10} \mathrm{cfu} / \mathrm{g}$, respectively $(\mathrm{P}<0.01)$. Total bacterial load was significantly reduced $(\mathrm{P}<0.01)$ after washing with disinfectant solutions as compared to unwashed vegetables.

Table 2 shows total coliform count in vegetables before and after washing vegetables with filter water and disinfectant solutions. Total coliform counts in vegetables without wash ranged from $7.61 \pm 0.34$ to $7.13 \pm 0.13 \log _{10} \mathrm{cfu} / \mathrm{g}$. The counts of total coliforms were significantly reduced after tap water and filter water and disinfectant solution wash $(\mathrm{P}<0.01)$. The mixed solution of 
Table 1. Counts of total heterotrophic bacteria in vegetables before and after washing with water and disinfectant solutions

\begin{tabular}{|c|c|c|c|c|c|c|}
\hline \multirow[t]{2}{*}{ Vegetable } & \multicolumn{6}{|c|}{ TypeBacterial load $\left(\log _{10} \mathrm{cfu} / \mathrm{g} \pm \mathrm{SD}\right)$} \\
\hline & WW & TW & FW & HT & BP & $\mathrm{BP}+\mathrm{CA}$ \\
\hline Potato & $8.65 \pm 0.53$ & $7.61 \pm 0.37$ & $6.27 \pm 0.63$ & $4.60 \pm 0.39$ & $2.34 \pm 1.61$ & NG \\
\hline Carrot & $8.74 \pm 0.71$ & $7.13 \pm 0.39$ & $5.76 \pm 0.88$ & $3.83 \pm 1.26$ & $1.80 \pm 1.61$ & $\mathrm{NG}$ \\
\hline Cucumber & $8.71 \pm 0.67$ & $7.51 \pm 0.44$ & $6.16 \pm 0.47$ & $3.84 \pm 0.86$ & $1.92 \pm 0.82$ & $\mathrm{NG}$ \\
\hline Egg Plant & $8.50 \pm 0.77$ & $6.84 \pm 0.47$ & $5.14 \pm 0.43$ & $2.79 \pm 0.55$ & $1.25 \pm 0.96$ & $\mathrm{NG}$ \\
\hline Cauliflower & $8.71 \pm 0.66$ & $7.44 \pm 0.37$ & $5.90 \pm 0.51$ & $3.54 \pm 1.01$ & $1.65 \pm 1.30$ & NG \\
\hline Turnip & $9.05 \pm 0.39$ & $7.60 \pm 0.45$ & $6.34 \pm 0.51$ & $3.32 \pm 1.55$ & 1.661 .54 & NG \\
\hline Radish & $8.44 \pm 0.47$ & $7.59 \pm 0.32$ & $5.99 \pm 0.63$ & $4.50 \pm 0.35$ & $1.81 \pm 1.28$ & NG \\
\hline Papaya & $8.96 \pm 0.48$ & $7.80 \pm 0.56$ & $5.69 \pm 0.75$ & $3.30 \pm 1.35$ & $1.57 \pm 1.51$ & NG \\
\hline Bitter Gourd & $8.33 \pm 0.49$ & $6.84 \pm 0.47$ & $5.15 \pm 0.44$ & $2.79 \pm 0.55$ & $1.25 \pm 0.96$ & NG \\
\hline Snake Gourd & $8.87 \pm 0.31$ & $7.54 \pm 0.39$ & $5.89 \pm 0.55$ & $3.53 \pm 1.01$ & $1.65 \pm 1.30$ & $\mathrm{NG}$ \\
\hline Ridge Gourd & $9.07 \pm 0.19$ & $7.51 \pm 0.50$ & $6.33 \pm 0.55$ & $3.27 \pm 1.47$ & $1.25 \pm 0.96$ & $\mathrm{NG}$ \\
\hline
\end{tabular}

Legend: WW, Without Wash; TW, Tap Water; FW, Filtered Water; HTW, Halo Tab Water; BP, Bleaching Powder (0.2\%); BP+CA, Bleaching Powder $(0.2 \%)+$ Citric Acid (0.1\%); NG, No Growth

bleaching powder and citric acid was found to completely inactivate microorganisms and did not show any growth after subculture.
Table 3 shows the counts of total Enterobacteriaceae in vegetable samples before and after washing steps using tap water, filtered water and different disinfectant solutions. Washing with tap water

Table 2. Counts of total coliforms in vegetables before and after washing with water and disinfectant solutions

\begin{tabular}{lcccccc}
\hline Vegetable & \multicolumn{5}{c}{ TypeBacterial load $\left(\log _{10}\right.$ cfu/g \pm SD $)$} \\
\cline { 2 - 7 } & WW & TW & FW & HT & BP & BP+CA \\
\hline Potato & $7.27 \pm 0.19$ & $6.07 \pm 0.18$ & $4.53 \pm 0.47$ & $2.43 \pm 0.44$ & $1.06 \pm 0.91$ & NG \\
Tomato & $7.25 \pm 0.30$ & $6.27 \pm 0.73$ & $4.43 \pm 0.98$ & $2.34 \pm 0.40$ & $0.25 \pm 0.50$ & NG \\
Carrot & $7.49 \pm 0.30$ & $6.19 \pm 0.15$ & $5.13 \pm 0.15$ & $3.09 \pm 1.17$ & $0.88 \pm 0.63$ & NG \\
Cucumber & $7.61 \pm 0.34$ & $5.92 \pm 0.41$ & $4.98 \pm 0.66$ & $2.54 \pm 0.60$ & $1.01 \pm 0.82$ & NG \\
Green Chili & $7.42 \pm 0.44$ & $6.11 \pm 0.59$ & $4.39 \pm 0.57$ & $2.33 \pm 0.29$ & $0.50 \pm 0.58$ & NG \\
Bean & $7.30 \pm 0.34$ & $5.55 \pm 0.45$ & $4.41 \pm 0.49$ & $2.42 \pm 0.83$ & $1.29 \pm 0.89$ & NG \\
Egg Plant & $7.49 \pm 0.41$ & $5.86 \pm 0.46$ & $4.16 \pm 0.47$ & $2.81 \pm 0.40$ & $0.75 \pm 0.96$ & NG \\
Cauliflower & $7.47 \pm 0.38$ & $6.00 \pm 0.68$ & $3.69 \pm 0.45$ & $2.47 \pm 0.48$ & $0.27 \pm 0.55$ & NG \\
Turnip & $7.44 \pm 0.36$ & $5.91 \pm 0.28$ & $4.31 \pm 0.68$ & $2.39 \pm 0.71$ & $0.75 \pm 0.96$ & NG \\
Radish & $7.13 \pm 0.13$ & $5.28 \pm 0.23$ & $3.88 \pm 0.52$ & $2.54 \pm 0.54$ & $1.06 \pm 0.91$ & NG \\
Capsicum & $7.55 \pm 0.31$ & $5.18 \pm 0.15$ & $3.60 \pm 0.53$ & $2.01 \pm 0.01$ & $0.50 \pm 0.58$ & NG \\
Pumpkin & $7.46 \pm 0.33$ & $5.80 \pm 0.75$ & $4.42 \pm 0.72$ & $2.69 \pm 0.72$ & $1.00 \pm 1.15$ & NG \\
Cabbage & $7.20 \pm 0.15$ & $5.86 \pm 0.45$ & $4.13 \pm 0.13$ & $2.74 \pm 0.41$ & $1.13 \pm 0.85$ & NG \\
Gourd & $7.60 \pm 0.28$ & $5.13 \pm 0.83$ & $3.89 \pm 0.59$ & $2.32 \pm 0.46$ & $0.75 \pm 0.96$ & NG \\
Papaya & $7.46 \pm 0.30$ & $5.33 \pm 0.37$ & $3.72 \pm 0.48$ & $2.01 \pm 0.02$ & $0.50 \pm 0.58$ & NG \\
Bitter Gourd & $7.31 \pm 0.34$ & $5.47 \pm 0.28$ & $3.50 \pm 0.52$ & $2.56 \pm 0.52$ & $0.25 \pm 0.50$ & NG \\
Snake Gourd & $7.15 \pm 0.26$ & $5.26 \pm 0.30$ & $3.56 \pm 0.46$ & $2.13 \pm 0.25$ & $0.25 \pm 0.50$ & NG \\
Ridge Gourd & $7.33 \pm 0.39$ & $5.39 \pm 0.45$ & $3.91 \pm 1.04$ & $2.35 \pm 0.44$ & $0.76 \pm 0.51$ & NG \\
\hline
\end{tabular}

Legend: WW, Without Wash; TW, Tap Water; FW, Filter Water; HTW, Halo Tab Water; BP, Bleaching Powder $(0.2 \%)$; BP+CA, Bleaching Powder $(0.2 \%)+$ Citric Acid (0.1\%); NG, No Growth 
Table 3. Count of total Enterobacteriacae in vegetables before and after washing with water and disinfectant solutions

\begin{tabular}{|c|c|c|c|c|c|c|}
\hline \multirow[t]{2}{*}{ Vegetable } & \multicolumn{6}{|c|}{ TypeBacterial load $\left(\log _{10} \mathrm{cfu} / \mathrm{g} \pm \mathrm{SD}\right)$} \\
\hline & WW & TW & FW & HT & $\mathrm{BP}$ & $\mathrm{BP}+\mathrm{CA}$ \\
\hline Potato & $7.52 \pm 0.5$ & $6.38 \pm 0.45$ & $5.22 \pm 1.04$ & $3.40 \pm 0.89$ & $1.06 \pm 0.91$ & $\mathrm{NG}$ \\
\hline Tomato & $7.56 \pm 0.41$ & $6.22 \pm 0.48$ & $4.79 \pm 0.36$ & $2.37 \pm 0.44$ & $0.64 \pm 0.77$ & NG \\
\hline Carrot & $8.04 \pm 0.33$ & $6.38 \pm 0.43$ & $5.07 \pm 0.11$ & $3.21 \pm 1.10$ & $1.13 \pm 0.94$ & NG \\
\hline Cucumber & $7.74 \pm 0.37$ & $6.48 \pm 0.37$ & $5.53 \pm 0.46$ & $3.11 \pm 0.86$ & $1.66 \pm 0.49$ & NG \\
\hline Green Chili & $7.48 \pm 0.37$ & $6.31 \pm 0.34$ & $4.91 \pm 0.62$ & $2.84 \pm 0.68$ & $0.75 \pm 0.96$ & NG \\
\hline Bean & $7.55 \pm 0.61$ & $6.28 \pm 0.96$ & $4.73 \pm 0.57$ & $3.06 \pm 0.91$ & $1.18 \pm 0.89$ & NG \\
\hline Egg Plant & $7.75 \pm 0.29$ & $6.20 \pm 0.13$ & $4.39 \pm 1.30$ & $2.75 \pm 0.50$ & $1.25 \pm 0.96$ & NG \\
\hline Cauliflower & $7.49 \pm 0.41$ & $6.57 \pm 0.66$ & $4.74 \pm 0.58$ & $2.99 \pm 0.81$ & $0.65 \pm 1.30$ & NG \\
\hline Turnip & $7.67 \pm 0.39$ & $6.55 \pm 0.61$ & $5.48 \pm 0.14$ & $2.89 \pm 1.00$ & $1.25 \pm 0.96$ & NG \\
\hline Radish & $7.24 \pm 0.31$ & $5.95 \pm 0.47$ & $4.68 \pm 0.62$ & $2.66 \pm 0.73$ & $1.06 \pm 0.91$ & NG \\
\hline Capsicum & $7.65 \pm 0.38$ & $6.05 \pm 0.22$ & $4.63 \pm 0.46$ & $2.37 \pm 0.44$ & $0.64 \pm 0.77$ & NG \\
\hline Pumpkin & $7.61 \pm 0.36$ & $6.18 \pm 0.13$ & $5.05 \pm 0.07$ & $3.24 \pm 1.12$ & $1.00 \pm 0.82$ & NG \\
\hline Cabbage & $7.20 \pm 0.14$ & $6.09 \pm 0.07$ & $4.83 \pm 0.49$ & $2.81 \pm 0.97$ & $1.63 \pm 0.48$ & NG \\
\hline Gourd & $7.44 \pm 0.46$ & $6.09 \pm 0.17$ & $4.85 \pm 0.57$ & $2.90 \pm 0.71$ & $0.75 \pm 0.96$ & NG \\
\hline Papaya & $7.58 \pm 0.42$ & $5.64 \pm 0.65$ & $4.10 \pm 0.40$ & $2.75 \pm 0.50$ & $1.16 \pm 0.87$ & NG \\
\hline Bitter Gourd & $7.35 \pm 0.42$ & $5.90 \pm 0.37$ & $3.97 \pm 0.65$ & $2.55 \pm 0.60$ & $0.75 \pm 0.96$ & NG \\
\hline Snake Gourd & $7.85 \pm 0.27$ & $6.38 \pm 0.78$ & $4.34 \pm 0.85$ & $2.73 \pm 0.51$ & $0.27 \pm 0.55$ & NG \\
\hline Ridge Gourd & $7.46 \pm 0.38$ & $5.97 \pm 0.59$ & $4.36 \pm 1.02$ & $2.58 \pm 0.62$ & $1.25 \pm 0.96$ & NG \\
\hline
\end{tabular}

Legend: WW, Without Wash; TW, Tap Water; FW, Filter Water; HTW, Halo Tab Water; BP, Bleaching Powder $(0.2 \%)$; BP+CA, Bleaching Powder $(0.2 \%)+$ Citric Acid (0.1\%); NG, No Growth

and filtered water could reduce approximately $1.0-2.0 \log _{10} \mathrm{cfu} /$ g. There was significant reduction in total Enterobacteriaceae $(\mathrm{P}<0.01)$ when they were washed with halotab and bleaching powder solutions as compared to the unwashed samples. Washing with bleaching powder $(0.2 \%)$ solution could reduce the count of Enterobacteriaceae which ranged between $1.66 \pm 0.49$ and $0.27 \pm 0.55 \log _{10} \mathrm{cfu} / \mathrm{g}$. However, no growth of Enterobacteriaceae was found when vegetables were washed with bleaching powder $(0.2 \%)$ and citric acid $(0.1 \%)$ solution.

Conventional washing and sanitizing methods are not capable of reducing microbial loads by more than 90 or $99 \%$, although greater efficacy is required to assure product safety ${ }^{13}$. Washing technique was used on fresh tomatoes in major markets in South-eastern Nigeria which was found to be inefficient leaving high level of microbial contamination. However, potable water obtained from bore-holes may demonstrate contamination from bacterial and fungal species. Bacterial isolates may include Bacillus cereus, Lactobacillus spp. and Staphylococcus aureus. The fungal isolates consist of Penicillum spp., Aspergillus niger and A. oryzae. Microorganisms can enter the fruit through osmotic action from wash water contaminated from dirty soil and organic materials. Microbiological quality of fresh fruits and vegetables can also be affected by the postharvest handling e.g. packaging and storage condition. It is therefore, necessary to ensure good quality of water especially in areas with inadequate or no cold-chain.

Fresh-cut fruits and vegetables can be easily contaminated from the surrounding microorganisms present in the environment which may cause degradation of processed fruit items ${ }^{17}$. Sanitation of such items by adding sanitizers in wash water was found to reduce microbial counts and helped to maintain quality and extend shelflife of such products. Other researchers used Chlorine Dioxide for washing fresh-cut vegetables to determine their bactericidal effect and role in browning reactions in fruits and vegetables ${ }^{18}$. Samples were dipped an washed in 50, 100 and $200 \mathrm{ppm}$ concentrations of bactericide solutions for 20 minutes and stored for 0, 1, 2, 4 and 7 days. Samples were subsequently checked for microbial content (total heterotrophic bacteria, coliform, E. coli, yeasts and molds count) and browning reaction. They showed that $100 \mathrm{ppm} \mathrm{ClO}_{2}$ solution could reduce 3.5- $4.0 \log \mathrm{CFU} / \mathrm{g}$ in total bacterial and coliform counts on lettuce, carrot and tomato which was found to be better than sodium hypochlorite solution treatment $(\mathrm{p}<0.05)$. As for the browning test, the apple slices treated with $50 \mathrm{ppm} \mathrm{ClO}_{2}$ solution showed anti browning effects, but carrot slices treated with $200 \mathrm{ppm} \mathrm{ClO}_{2}$ solution displayed a fading effect. Gas chromatography-mass spectrometry (GC-MS) analysis also showed that using a $200 \mathrm{ppm} \mathrm{ClO}_{2}$ bactericide solution for 20 minutes, results in $12.85 \mathrm{ppb}$ residuary trihalomethans (THMs) which was lower than $\mathrm{NaOCl}$ treatment (142 ppb residuary THMs). Chlorine dioxide $\left(\mathrm{ClO}_{2}\right)$ is a strong oxidizing agent and a safe bactericide, and generates only a small amount of THMs as a byproduct. The treatment of $\mathrm{ClO}_{2}$ solution for fresh-cut vegetables and fruits also conform to the Taiwan environment protection regulation, which suggests THMs counts be lower than $80 \mathrm{ppb}$. 
Another researcher conducted a study to monitor the prevalence of microorganisms, heavy metal contents and vitamins in raw red-amaranth and the impact of cooking on microorganisms, heavy metal contents and vitamins of red amaranth ${ }^{19}$. At the beginning of that study average counts of total coliforms and total viable bacterial loads were found to be $7.0 \log _{10} \mathrm{CFU} / \mathrm{g}$, and $>8.0 \log _{10} \mathrm{CFU} / \mathrm{g}$, respectively in raw amaranth samples. Samples were also found to be contaminated with notable pathogens like Salmonella spp., Escherichia coli, Listeria spp. and Yersinia spp. Washing amaranth samples with scallop powder and distilled water were found to reduce 1.0-1.5 $\log _{10} \mathrm{CFU} / \mathrm{g}$ of both types of bacteria. An additional washing with chlorine water (200 ppm) could reduce additional $2.0 \log _{10} \mathrm{CFU} / \mathrm{g}$. Washing with water alone did not show any reduction in bacterial counts in red amaranth. However, cooking these samples at $90^{\circ} \mathrm{C}$ for $15 \mathrm{~min}$ demonstrated $5.0 \log _{10} \mathrm{CFU} / \mathrm{g}$ reduction in viable bacterial load. Cooking was recorded as a successful method for eliminating coliforms and the above mentioned pathogenic bacteria from the studied samples.

In this study vegetable samples were washed with water and disinfectant solutions to determine the washing effects by enumerating bacterial loads. It was revealed that vegetable samples before any kind of washing showed more colonies compared to those after washing with water or disinfectant solutions. Bacterial loads were higher after washing with tap water compared to those of filter water. In case of green chilli, an important salad item, total bacterial load was recorded highest $9.07 \pm 0.41 \log _{10} \mathrm{cfu} / \mathrm{g}$ in unwashed samples which was subsequently reduced below detection level after Bleaching powder $(0.2 \%)+$ Citric acid $(0.1 \%)$ wash. Halotab ${ }^{\mathrm{TM}}(15 \mathrm{mg})$ solution wash was found to be more efficient than tap water. It was not more than bleaching powder $(0.2 \%)$ solution wash. Similar counts of total coliforms and Enterobacteriaceae were determined after different washing types of washing of vegetable samples on mFC and Violet Red Bile Salt Glucose (VRBG) agar, respectively. In case of beans total coliform counts after bleaching powder $(0.2 \%)$ and bleaching powder $(0.2 \%)+$ citric acid $(0.1 \%)$ wash were $1.29 \pm 0.89 \log _{10} \mathrm{cfu} / \mathrm{g}$ and 0 , respectively. In the same sample counts of Enterobacteriaceae subsequent to bleaching powder and bleaching powder $(0.2 \%)+$ citric acid $(0.1 \%)$ wash were determined to be $1.18 \pm 0.89 \log _{10} \mathrm{cfu} / \mathrm{g}$ and 0 , respectively. However, tap water is commonly used for washing vegetables and other fresh fruits rather than disinfectant solutions in Bangladesh. Since washing fresh vegetables either using tap or filtered water were not found to be effective in reducing bacterial load, it may be suggested that disinfectant solutions would be the alternative solutions. This study showed the reduction of bacterial loads simply by washing fresh vegetables using different types of disinfectant solutions and water.

Ready to eat (RTE) foods are often contaminated during processing and subsequent to production. They may get contaminated from dirty water used for washing, unclean equipment use for processing vegetables and not following the rules of Good Manufacturing Practice (GMP). Contamination may also be linked to inadequate or faulty processing and storage condition such as, faulty pasteurization equipment and monitoring devices. According to the WHO 25\% of food borne outbreaks in Europe has been linked to recontamination of foods ${ }^{20}$. Irrigation water and fertilizers used during cultivation of vegetables were frequently reported to contain coliforms and other enteric bacteria $^{21}$. Therefore, presence of coliforms and pathogenic bacteria in vegetables indicate poor washing and sanitation before processing. Washing with suitable disinfectants may be recommended to avoid food borne illness and outbreaks associated with fresh fruits and vegetables.

It is therefore necessary to understand the mechanisms by which attached bacteria resist detachment or inactivation in order to improve the efficacy of washing vegetables especially for reducing pathogenic bacteria. Additional knowledge of the physiological state of attached bacteria, their attachment sites, their interactions with the plant surface, other microorganisms, and their sensitivity to antimicrobial agents will also be useful. For developing new or improved washing and sanitizing treatments for fruits and vegetables, it is important to take into account the compatibility of treatments with commercial practices, treatment costs and adverse effects on product quality due to the treatment, regulatory approval and consumer acceptance.

Washing and disinfectants treatment can play an important role in reducing microbial populations associated with food borne outbreaks on fresh vegetables intended for fresh market or freshcut processing, thereby improving product quality and safety. Conventional washing of vegetables including tap water and filter water can't reduce the bacterial load to satisfactory level. Additionally, some fresh vegetables are consumed raw as salad items and sometimes treated with little heat which may lead to outbreak of disease. So, new washing technologies using more effective sanitizing or disinfecting agents are needed to kill microorganisms that may survive conventional washing systems. For this purpose Bleaching Powder $(0.2 \%)$ or Bleaching Powder $(0.2 \%)+$ Citric Acid $(0.1 \%)$ solutions can be an effective disinfectant to limit the total bacterial load in vegetables over the conventional washing procedure. Commercialization of new and effective approaches for disinfection will improve the microbiological quality and safety of fresh and fresh-cut vegetables.

\section{References}

1. Hamilton AJ, Stagnitti F, Premier R, Boland AM and Hale G. 2006. Quantitative microbial risk assessment models for consumption of raw vegetables irrigated with reclaimed water. Appl. Environ. Microbiol. 72: 3284-3290.

2. Soriano JM, Rico H, Molto JC and Ma J. 2001. Incidence of microbial flora in lettuce, meat and Spanish potato omelette from restaurant. Food Microbiol. 18: 159-163. 
Das et. al.

3. Amoah P, Drechsel P, Abidoo RC and Abraham EM. 2009. Improving food hygiene in Africa where vegetables are irrigated with polluted water. Regional Sanitation and Hygiene Symposium, 3-5 Nov. 2009, Accra, Ghana.

4. Heaton JC and Jones K. 2008. Microbial contamination of fruit and vegetables and the behaviour of enteropathogens in the phyllosphere: a review. J. Appl. Microbiol. 104: 613-626.

5. Polcovnicu C, Ionescu L and Bahrim G. 2008. Confirmation and identification of Listeria species from fresh lettuce. Romanian Biotech. Lett. 13(6): 32-36.

6. Harris LJ, Faber JN, Beuchat LR, Parish ME, Suslow TB, Garret EH and Busta FF. 2003. Outbreaks associated with fresh produce: incidence, growth and survival of pathogens in fresh and fresh cut produce. Comp. Rev. Food Sci. Food Safety. 2: 115-119.

7. Sahilah AM, Suraya T, Noraida I, Azuhairi A, Chai LC and Son R. 2010. Detection of virulence genes and enterobacterial repetitive intergenic consensus-PCR (ERIC-PCR) analysis among raw vegetables isolates of Campylobacter jejuni. Int. Food Res. J. 17: 681- 690.

8. Fremaux B, Delignette-Muller ML, Prigent-combaret C, Gleizal A, vernozy-Rozand C. 2007. Growth and Survival of non-O157:H7 shigatoxin- producing E. coli in cow manure. J. Appl. Microbiol. 102: 89-99.

9. van Alphen LB, Dorle' ans F, Schultz AC, Fonager J, Ethelberg S, Dalgaard C, Adelhardt M, Engberg JH, Fischer TK and Lassen SG. 2014. The Application of New Molecular Methods in the Investigation of a Waterborne Outbreak of Norovirus in Denmark, 2012. PLoS ONE. 9(9): e105053. doi:10.1371/journal.pone.0105053.

10. FAO/WHO. 2004. Fruit and Vegetables for Health: In Joint FAO/WHO workshop on fruit and vegetables for health. Fruit and vegetables for health: report of a Joint FAO/WHO workshop, Kobe, Japan. 1-39.

11. Centers for Disease Control and Prevention (CDC). 2014. Estimates of Foodborne Illness in the United States. Available at: http:/www.cdc.gov/ foodborneburden/2011-foodborne-estimates.html\#annual, (Accessed on $22^{\text {nd }}$ December, 2018).
12. Pennington H. 2011. Escherichia coli O104, Germany. Lancet Infect. Dis. 11: 652-653.

13. Sapers GM. 2001. Efficacy of Washing and Sanitizing Methods. Food Technol. Biotechnol. 39(4) 305-311.

14. American Public Health Association (APHA). 2012. Standard Methods for the Examination of Water \& Wastewater, 22nd Ed., American Water Works Association (AWWA) \& Water Environment Federation (WEF).

15. Hernandez-Brenes, C. 2002. The importance of training for improving the safety and quality of fresh fruits and vegetables, In: Improving the safety and quality of fresh fruits and vegetables: A training manual for trainers. University of Maryland.

16. Lund BM. 1992. Ecosystems in vegetable foods. J. Appl. Bacteriol. 73: 115-135.

17. Nicola S, Tibaldi G and Fontana E. 2009. Fresh-cut produce quality: Implications for a systems approach. In: Florkowski WJ, Shewfelt RL, Brueckner B and Prussia SE (eds.) Postharvest handling. Academic Press, New York, pp 247-282.

18. Chung C, Huang T, Yu C, Shen F and Chen H. 2011. Bactericidal Effects of Fresh-Cut Vegetables and Fruits after Subsequent Washing with Chlorine Dioxide. International Conference on Food Engineering and Biotechnology IPCBEE vol.9 IACSIT Press, Singapoore.

19. Mamun MAA, Simu HA, Rahman A, Gazi NN and Bari ML. 2012. Prevalence of Foodborne Pathogens and Effectiveness of Washing or Cooking in Reducing Microbiological Risk of Contaminated Red Amaranth. Agri. Food Anal. Bacteriol. 2: 222-231.

20. WHO (World Health Organization). 1995. Surveillance Program. Sixth Report of WHO Surveillance Program for Control of Foodborne Infections and Intoxications in Europe. FAO/WHO Collaborating Centre for Research and Training in Food Hygiene and Zoonosis, Berlin.

21. Gagliardi JV and Karns JS. 2000. Leaching of Escherichia coli O157: H7 in Diverse Soils under Various Agricultural Management Practices. Appl. Environ. Microbiol. 6(3): 877-883. 